Article

\title{
Increasing Energy Efficiency in Water Collection Systems by Submersible PMSM Well Pumps
}

\author{
Marcus Beck ${ }^{1, *}$, Alexander Sperlich ${ }^{2}\left(\mathbb{D}\right.$, Ricardo Blank ${ }^{3}$, Eckehard Meyer ${ }^{3}$, Ralf Binz ${ }^{2}$ and \\ Mathias Ernst ${ }^{1}$ (D) \\ 1 DVGW Research Centre at the Hamburg University of Technology, Am Schwarzenberg-Campus 3, \\ 21073 Hamburg, Germany; mathias.ernst@tuhh.de \\ 2 Berliner Wasserbetriebe, 10864 Berlin, Germany; alexander.sperlich@bwb.de (A.S.); Ralf.Binz@bwb.de (R.B.) \\ 3 Hamburger Wasserwerke GmbH, 20539 Hamburg, Germany; Ricardo.Blank@hamburgwasser.de (R.B.); \\ Eckehard.Meyer@hamburgwasser.de (E.M.) \\ * Correspondence: marcus.beck@tuhh.de; Tel.: +49-(0)40-42878-3453
}

Received: 5 July 2018; Accepted: 18 September 2018; Published: 22 September 2018

check for updates

\begin{abstract}
Water collection based on groundwater abstraction has a high energy consumption that depends primarily on the operation and performance of submersible well pumps. The fact of the matter is that these machines still work with a global energy efficiency of less than $50 \%$, and further investigations of the energy aspects in well pumps are needed. The present study introduces measures to increase the global efficiency of submersible well pumps linked to electrical energy savings. Common submersible pumps with asynchronous motors (ASMs) were compared with innovative permanent magnet synchronous motor (PMSM) technology in real well fields in Berlin and Hamburg waterworks. This study confirms that PMSM pumps showed a 6.8\%-points higher global efficiency compared to ASM pumps at optimal working points. The investigation of the impact of well field operation on local pump efficiency offers an additional increase in the global efficiency. In this context, the influence of variable speed control on the global efficiency and the energy consumption was analyzed. Global efficiencies of over $70 \%$, and potential energy savings of up to $20 \%$, were determined for the speed-controlled PMSM pump. This offers water suppliers new incentives to optimize their water collection systems for less energy consumption.
\end{abstract}

Keywords: electrical submersible pumps; permanent magnet synchronous motor; variable-speed operation; optimizing working points; energy efficiency; water collection

\section{Introduction}

The average specific energy consumption in the German water supply companies amounts to approximately $0.5 \mathrm{kWh} / \mathrm{m}^{3}$ [1]. This results in a total share of primary energy consumption of about 0.53\% (data from 2013), corresponding to approximately 2400 GWh of electrical energy [2]. About $70 \%$ of the German water supply originates from groundwater. Submersible pumps deliver the water from deep wells (from $30 \mathrm{~m}$ up to $350 \mathrm{~m}$ depth) and transport it over considerable distances (from $100 \mathrm{~m}$ up to $20 \mathrm{~km}$ ), via raw water pipe networks, to the local water works. According to an internal analysis, water collection systems require 35-40\% of the total energy demand in the water supply [3]. The amount of water to be abstracted from groundwater wells depends on the local water demand. As a consequence, the well field flow rates are different in the dry and wet periods. The water suppliers react with an individual well field management. The common widely applied strategy for controlling the well field flow conditions is by shutting on, or off, the required number of submersible well pumps. With every combination of operating pumps, in each local well, the groundwater level, pressure, and flow states in the pipe network interact. A consideration of the large variety of flow and pressure 
levels apart from the water quality leads to complex operation conditions and challenges with respect to the optimization of the raw water system $[4,5]$.

The main components of a deep well pump system include several inherent components: a hydraulic structure, a motor, and a frequency converter (if installed), with individual specific energy losses (Figure 1). The global efficiency of the pump system is characterized by the performance of each of these components [6,7]. In most of the groundwater wells, asynchronous motors (ASMs) are used as conventional drive technology for submersible pumps. These pumps show relatively low global efficiencies, resulting in high electrical energy losses for the overall water collection system $[8,9]$. Other reasons for the low energy efficiencies are pressure losses in the raw water networks due to $\mathrm{Fe} / \mathrm{Mn}$ deposits (i), installations and fittings with high flow resistances (ii), and non-energy efficient well field operation (iii) [4]. The energy consumption of a conventional well pump may amount to $90 \%$ of total life-cycle costs after an operating time of 10 years [10]. Accordingly, measures to reduce energy consumption are of high relevance, especially as increasing prices of electrical energy must be considered.

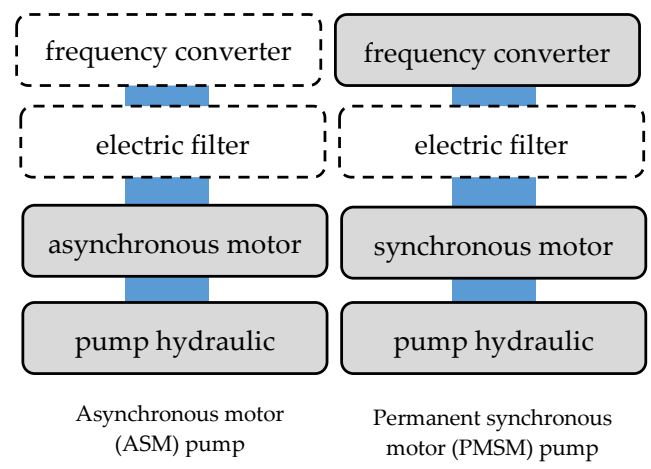

Figure 1. Mandatory (grey) and optional (white) components of submersible pump systems.

A recent survey of installed ASM pumps from different water suppliers summarizes that their average global efficiency is about $48 \%$, which is relatively low in comparison to centrifugal pumps applied in water treatment and supply systems (average value of 63\%) [11,12]. Staub [12] analyzed the distribution of the global efficiency for installed submersible pumps in Germany, with an efficiency of $<60 \%$ for $94 \%$ of the 2500 pumps that were analyzed (well pumps were included). Especially, small-sized submersible pumps may operate with a global efficiency of around only $20 \%$.

On the other hand, the European Directive 2009/125/EC new eco-design novella requires a maximum efficiency for energy-using units, such as electrical motors and pumps $[13,14]$. In 2014, the standard IEC 60034-30 defined the minimum efficiency performance ranges for ASM pumps [15]. In the beginning of 2016, the European Committee for Standardization (CEN) published the standard EN 16480, which defines a specific threshold value of a new parameter, the minimum efficiency index (MEI), especially for pump hydraulics, prohibiting sales of pumps with a MEI of less than 0.4 [16]. Currently, submersible well pumps are still not affected, but stricter requirements and standards for these machines are expected in the coming years [17]. Much better pump system efficiencies will be possible by applying the permanent magnet synchronous motor (PMSM) technique, an optimized hydraulic design, and surface coatings on hydraulic parts [7,18].

The ASM generally consists of a stator made of copper windings, and an aluminum short circuit rotor. The movement of the $\mathrm{Cu}$-rotor is induced within a magnetic field. The asynchronous rotating field between the rotor and stator has an energy loss due to slippage [19]. Permanent magnets are used in the PMSM pump rather than rotor windings in conventional ASM pumps. This technical alteration results in synchronous rotating fields without slippage, and it provides a technical advantage over ASM pumps. PMSM pump systems always need a frequency converter (Figure 1). With the development of new energy efficient submersible pump systems using PMSMs and their launch on 
the market in 2014, manufacturers are claiming an efficiency increase of up to $10 \%$, compared to the newest ASM technology. A significant higher global efficiency of up to $75 \%$ should be possible $[18,20]$.

Water utilities have little experience with these new submersible PMSM pump systems. Practical tests to investigate the actual achievable global efficiency in real well field operations are needed. This will induce further changes in the infrastructure of well chambers and maintenances. The need for a frequency converter and additional electrical components brings new operational risks and failures. Moreover, the additional components require electricity, and they reduce the overall energy efficiency by a fraction. Maintenance is also more complex for PMSM pump systems [9].

The positive aspects for frequency converters coming with PMSM pumps is the ability for variable-speed operation [21]. If compatible, they can also run together with ASM pumps (Figure 1). This offers the adaption of working points for pump operation on local water demand in each well, and allows for the adaption of possible new operation scenarios regarding energy saving for the water utility $[5,22]$.

Recent pump analyses of the water utilities in Hamburg (Hamburg Wasser) and in Berlin (Berliner Wasserbetriebe) reveal that based on the installed ASM well pump data, the global efficiencies will range between $57 \%$ and $65 \%$. However, a real operation energy analysis exhibited significantly lower global efficiencies (average 52\%). This needs further investigation to understand the behavior of the pumps working together in a well field with various demand. The water supplier has only limited data about the energy consumption or the global efficiency in water collection, because energy measurement was considered to be sufficient for the total water demand of a total well field, and not separate for each well. The local energy measurement focusing on each well, combined with the energy analyses, is a new approach. The implementation of additional sensors within a well system to collect detailed information on the intrinsic energy consumption and global efficiency of installed well pump is necessary for future analyses.

Despite the fact that reviews on energy recover analysis within drinking/irrigation water distributions systems are available [23], studies on energy efficiency in raw water collection systems are rare. The objective of the present study is to quantify global energy efficiency increases and real electrical energy savings that are currently achievable with state-of-the-art submersible pumps in a groundwater well, to give advice to water suppliers on increasing their global energy efficiency in water collection systems. Therefore, tests were performed with the innovative PMSM pump systems and compared with the common ASM pumps at two major German water utilities in Hamburg and Berlin. Moreover, the working points of the installed submersible well pumps were measured during well field operation with variable water demand, to investigate the impact on pump efficiency. Additionally, measures to increase the global energy efficiency by the application of frequency adjusted operations are suggested.

\section{Materials and Methods}

The strategies of well field management are comparable in Hamburg and Berlin. Both cities use simple automated routines that follow the cities' drinking water demands, and they apply intermittent operation of wells within their well fields. Each waterworks well field consists of numerous wells, ranging from 10 up to 120 wells. In general, both water suppliers use submersible ASM pumps, and only less than $10 \%$ are equipped with frequency converters.

To investigate the technical measures on energy efficiency, numerous measurements were performed in both cities at different waterworks. In the present study, the results of the waterworks Billbrook in Hamburg and the waterworks Tiefwerder in Berlin were presented.

Hamburg is $100 \%$ reliant on groundwater, which provides raw drinking water from lower lignite sand aquifers. The waterworks Billbrook is located close to the Elbe river bank in the eastern part of the city (Rothenburgsort). The investigated well is part of a well field with 10 other wells and is located within the industrial harbor area (next to Billbrook Canal). The well has a depth of $282 \mathrm{~m}$. The ascending pipe has a diameter of $0.2 \mathrm{~m}$. The submersible pump is positioned at a depth of $20 \mathrm{~m}$ 
from the ground surface (depth of water level during operation $10 \mathrm{~m}$ from the surface). Originally, the well was operated with a conventional ASM pump equipped with a frequency converter to ensure a constant flow rate. This was necessary because of dropping water levels during long-term operation. In such periods, the pump speed is steadily increased, resulting in overall higher energy consumption. Accordingly, the well infrastructure was ideal for investigations comparing the performance of modern ASM and PMSM pump systems, as only the pump hardware and the frequency converter had to be replaced. The new ASM pump system, as well as the PMSM system, came from the same manufacturer. First, the ASM pump was installed in the well, and after half a year of operation, it was exchanged by the PMSM pump system. Running the well pumps with an identical frequency converter and using identical hydraulic conditions offered the advantage that the energy losses of these components were nearly the same. To reduce the influence of water collection, a constant well field operation scenario was applied during measurements to maintain almost identical conditions for both pump systems. However, an additional electrical sinus filter was necessary for PMSM protection. The ASM pump could run without a sinus filter. The manufacturer data sheet specifies that the ASM pump has a global efficiency of $69 \%$ (motor $82.3 \%$ ), and the PMSM pump has a global efficiency of $74.6 \%$ (motor $90.2 \%$ ). An efficiency increase of $5.6 \%$-points could be expected based on the information provided by manufacturers.

In Berlin, the drinking water relies on bank filtrate originating from wells that are close to the river banks of the Havel and Spree rivers. These wells are located at a depth of 30 to $140 \mathrm{~m}$, and they derive groundwater with moderate contact time in the soil body (several weeks to one year). The investigated well is part of a well field with 20 other wells that supply waterworks Tiefwerder, located in the west of the city (Berlin-Spandau) close to the river Havel. The well has a depth of $42 \mathrm{~m}$. The ascending pipe has DN 150. A conventional submersible ASM pump (no frequency converter) is positioned at a depth of $15 \mathrm{~m}$ from the surface (the depth of water level during operation is $5 \mathrm{~m}$ from the surface). The well ran for 12 months with the original installed ASM pump, and for another 12 months with the adapted PMSM pump system. Like in Hamburg, the ASM pump was changed for the PMSM pump. The data of the first period was used to basically define the best operation point of the PMSM pump that was linked to the well field operation conditions. The well system then had the ability for variable speed operation. An additional measurement series analyzed the impact on energy consumption via reducing the speed and different operational scenarios, depending on the local water demand.

The campaigns in Hamburg Billbrook and Berlin Tiefwerder applied the same measurement concept (Figure 2). In most of the well chambers, analog instruments are available only to measure local pressure, water flow, and groundwater level. At both investigated well locations, additional sensors were necessary for effective power measurement. For this purpose, mobile measurement equipment was applied.

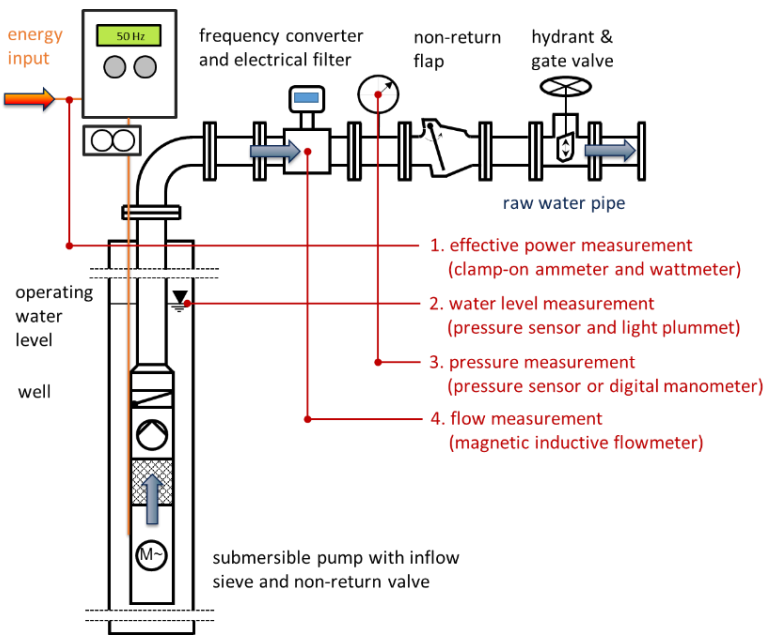

Figure 2. Measurement concept for data acquisition. 
Each measurement needed a controlled well field operation situation. This means that the well field ran the same wells next to the examined well for each operational scenario. To measure the complete working range of the installed submersible pump, the flow rate was controlled by throttling, using a gate valve at the local wellhead area. In the case of the present frequency converters, different speed levels were adjusted to analyze the consequences for a larger operation field.

Equations (1) and (2) represent the global efficiencies based on the collected measurement data and information about well geometrics. Equation (3) includes pressure losses:

$$
\begin{gathered}
\eta=\frac{P}{P_{e l}} \text { with } P=Q \cdot p_{\text {Ges }} \\
p_{\text {Ges }}=p+\left(h_{p}-h_{w}\right) \cdot \rho \cdot g+p_{J}(\mathrm{Q}) \\
p_{J}(Q)=\left[\lambda \cdot \frac{\left(h_{m}-h_{a}+l\right)}{d}+\sum\left(\zeta_{i}\right)\right] \cdot \frac{\rho \cdot v^{2}}{2}
\end{gathered}
$$

d: (m) inner pipe diameter

$g: \quad\left(\mathrm{m} / \mathrm{s}^{2}\right)$ gravitational constant

$h_{a}: \quad(\mathrm{mNN})$ position of pump outlet

$h_{m}: \quad(\mathrm{mNN})$ position of wellhead level

$h_{p}: \quad(\mathrm{mNN})$ position of pressure measurement point

$h_{w}:(\mathrm{mNN})$ position of groundwater level during operation

$l: \quad(m)$ length of horizontal distance between wellhead and pressure measurement point

$p$ : (bar) pressure at measurement point

$p_{J}(Q): \quad$ (bar) pressure losses depending on flow rate

$p_{\text {Ges: }}$ (bar) pressure at pump outlet

$P: \quad(\mathrm{kW})$ hydraulic power

$P_{e l}: \quad(\mathrm{kW})$ effective power at measurement point

Q: $\left(\mathrm{m}^{3} / \mathrm{h}\right)$ flow rate at measurement point

$v: \quad(\mathrm{m} / \mathrm{s})$ flow speed

$\zeta_{i}: \quad(-)$ drag coefficient of hydraulic component $i$

$\eta: \quad(-)$ global efficiency

$\lambda: \quad(-)$ friction factor

$\rho: \quad\left(\mathrm{kg} / \mathrm{m}^{3}\right)$ density of water $\left(\right.$ at $\left.15^{\circ} \mathrm{C}\right)$

The measured data gave information on the wellhead level, but both well pumps ran several meters below the groundwater level during operation. Accordingly, geodesic height (the difference between the pump outlet and the wellhead level) and pressure losses along the ascending pipe must be considered. Moreover, data provided by the water supply on pipe roughness, pipe dimensions, and the drag coefficients of existing installations (fittings, meters, slides, etc.) were taken into account for calculations.

\section{Results and Discussion}

\subsection{Measuring the Efficiencies of ASM vs PMSM}

In Hamburg Billbrook, each measurement scenario-the measure setup, as well as the well field configuration-was identical. As both pumps were equipped with frequency converters, systematic variation of the pump speed was possible to establish identical conditions with respect to pressure and flow.

Figure 3 presents the derived global efficiencies vs the measured flow at three different pump speeds: (a) $100 \%$, (b) $80 \%$, and (c) $60 \%$. As the pump speed decreased, the maximum global efficiency point in each scenario shifted to lower flow rates. In all scenarios, the PMSM submersible pump clearly 
showed a higher global efficiency than the ASM pump. Moreover, the difference in global efficiency performance between the two pump systems increased with decreasing pump speed.
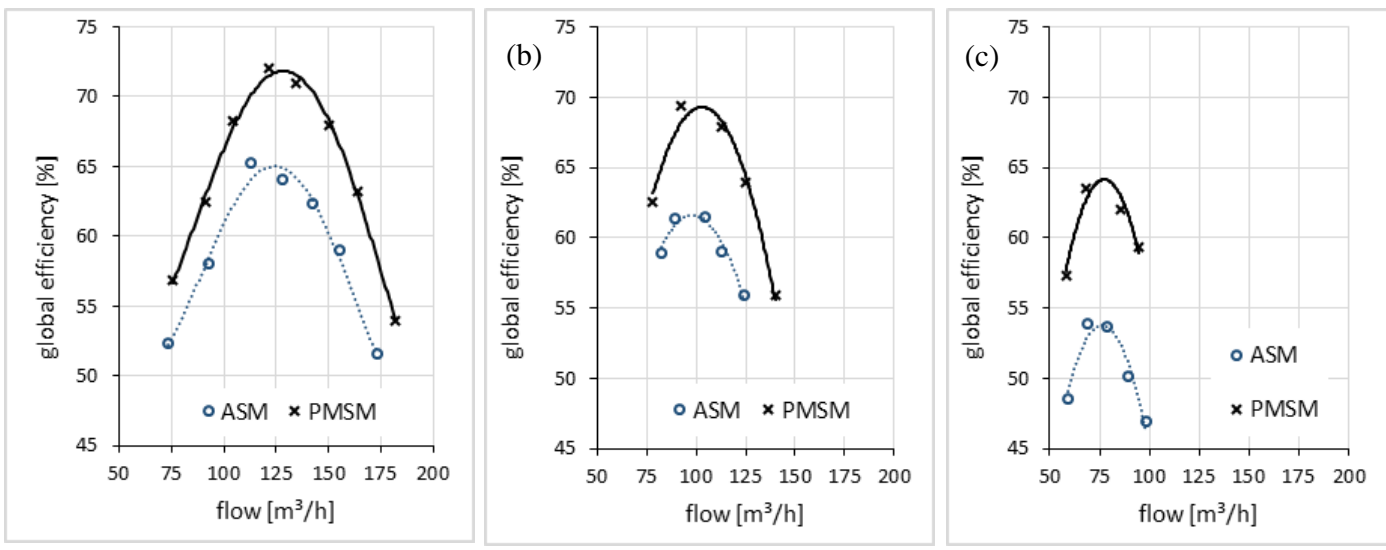

Figure 3. Global efficiencies of ASM and PMSM pumps at (a) $100 \%$, (b) $80 \%$, and (c) $60 \%$ speed.

The highest global efficiency was measured at a maximum speed, with $65.2 \%$ for the ASM pump and $72.0 \%$ for the PMSM pump, resulting in a 6.8\%-points higher efficiency for the latter (Figure 3a). At medium speed, the maximum ASM pump efficiency is $61.4 \%$ and $69.4 \%$ for the PMSM pump, respectively, resulting in a 8\%-points higher global efficiency for the PMSM pump (Figure 3b). At a low speed, the maximum global ASM pump efficiency is $53.9 \%$ vs $63.5 \%$ for the PMSM pump $(9.6 \%$-points higher efficiency, Figure 3c).

The results confirm that the PMSM pump system achieved higher global efficiencies than the ASM system for all measurements. Especially at a reduced speed level, the PMSM showed lower energy losses than ASM. Accordingly, PMSM was more interesting for variable speed applications. It is mentionable that the calculated efficiency data in the real well field was about $2 \%$-points lower than the manufacturer declared (Section 2). This difference was expected because of the unequal operational situation between the manufacturer test stand and the real well.

Figure 4 displays the specific energy consumption for each motor type at a maximum speed over the flow rate. The PMSM pump showed a lower specific energy consumption than the ASM pump. As the maximum global efficiencies for both pumps were at a flow rate of $120 \mathrm{~m}^{3} / \mathrm{h}$ (Figure $4 \mathrm{a}$ ), the highest specific energy consumption was measured at the lowest flow with the largest difference between the two pumps systems (exactly $0.017 \mathrm{kWh} / \mathrm{m}^{3}$ ). At higher flows, this difference shrank to $0.011 \mathrm{kWh} / \mathrm{m}^{3}$ at a flow rate of $170 \mathrm{~m}^{3} / \mathrm{h}$.

The resulting measured effective power consumption vs the flow of each pump showed a lower PMSM effective energy consumption, beginning with a difference of $1.2 \mathrm{~kW}$ for low flows, and steadily increasing up to $1.6 \mathrm{~kW}$ at a flow rate of $170 \mathrm{~m}^{3} / \mathrm{h}$ (Figure $4 \mathrm{~b}$ ). For the measured best efficiency point at a flow rate of $120 \mathrm{~m}^{3} / \mathrm{h}$, energy savings were approximately $1.6 \mathrm{~kW}$. Based on an ASM energy consumption of about $17.5 \mathrm{~kW}$ at the best efficiency point, the overall electrical energy demand was reduced by $9.3 \%$ with PMSM.

Table 1 further compares the data for ASM and PMSM pump systems, and quantifies the results at the best efficiency point with respect to the total annual energy and cost savings for the specific well in Hamburg Billbrook. With a determined difference in the global efficiencies of $6.8 \%$-points (Figure 3a) between both pump systems, this calculation amounted to $14 \mathrm{MWh}$ in energy savings per year, corresponding to annual savings of about $2200 €$ in pump operational costs if using the PMSM pump. Based on these results, an amortization of the higher investment cost for the PMSM system (excluding the costs for required infrastructure and additional equipment) will be possible within $3-4$ years. 


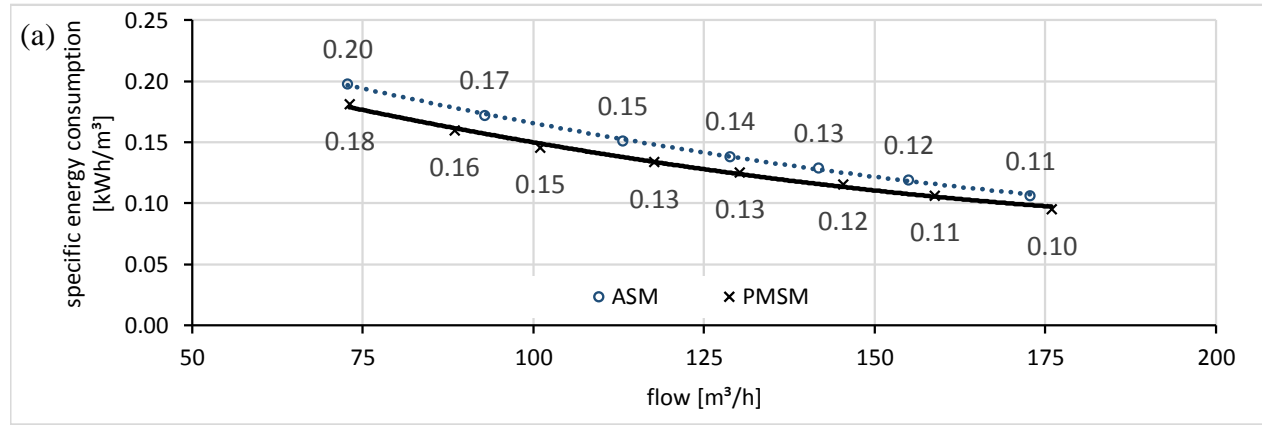

(b)

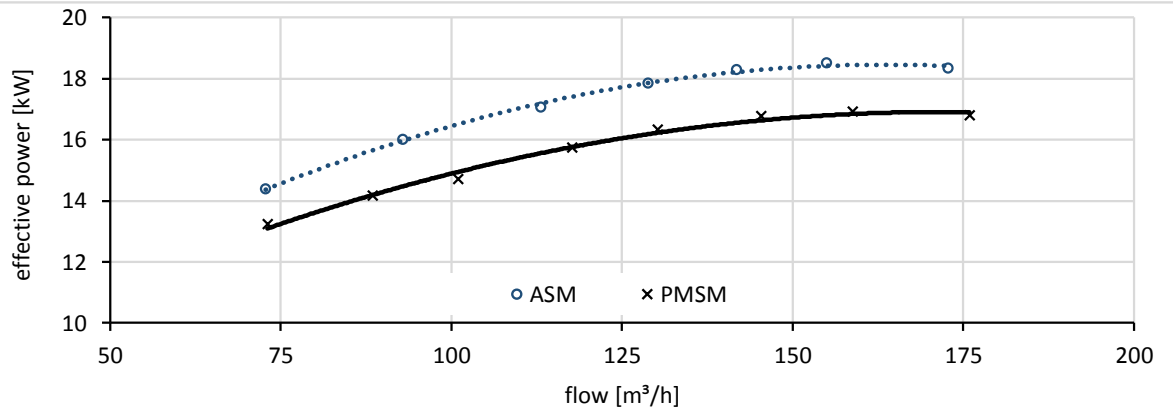

Figure 4. (a) Specific energy consumption and (b) effective power for the submersible ASM and PMSM pumps at $2900 \mathrm{rpm}$ (close to the optimal working point).

Table 1. Energy saving potential with global efficiency increase by the new PMSM well pump.

\begin{tabular}{cccc}
\hline Description & Unit & Before & After \\
\hline Flow & $\mathrm{m}^{3} / \mathrm{h}$ & 120 & 120 \\
Head & $\mathrm{m}$ & 35 & 35 \\
Hydraulic power & $\mathrm{kW}$ & 11.44 & 11.44 \\
Global efficiency & - & 0.652 & 0.72 \\
Power consumption & $\mathrm{kW}$ & 17.55 & 16.08 \\
Hours of operation & $\mathrm{h} / \mathrm{a}$ & 8000 & 8000 \\
Total energy consumption & $\mathrm{kWh} / \mathrm{a}$ & 140,425 & 126,811 \\
Electricity price & $€ / \mathrm{kWh}$ & 0.163 & 0.163 \\
Energy costs & $€ / \mathrm{a}$ & 22,889 & 20,670 \\
Energy saving potential & $€ / \mathrm{a}$ & $9.70 \%$ \\
Energy cost saving & $\mathrm{n}$ & 2219 \\
German energy mix 2016 & $\mathrm{kg} \mathrm{CO} / \mathrm{kW}$ & & 0.527 \\
$\mathrm{CO}_{2}$ saving & $\mathrm{kg} \mathrm{CO}_{2} / \mathrm{a}$ & 7175 \\
\hline
\end{tabular}

\subsection{Measuring the Efficiencies of ASMs at Different Well Field Demands}

In Berlin-Tiefwerder, the operational states of a conventional ASM pump (without frequency drive) were analyzed for a period of one year. The well was part of a larger well field that consisted of 20 wells. Depending on the number of parallel operating ASM pumps, the flow rate and pressure in the well field was different, and numerous working points for the investigated well pump were possible.

All of the working points of the ASM pump ranged between two extremes: the "dry period" state is usually applied in summer when a maximum volume flow during peak operation is required. In this state, all of the pumps in the well field were running, and the resulting pressure level for the investigated well ASM pump is relatively high, at about 4.5 bar (Figure 5, intercept point dry period). The other extreme is the "wet period" operation scenario. This is typical for winter when few pumps are running in the well field. Accordingly, the volume flow to the water works was relatively low, but the resulting flow of the analyzed well was higher at a considerably lower pressure level (Figure 5, intercept point wet period) compared with the wet period state. The investigated ASM pump operated 
for about $3500 \mathrm{~h}$ a year in the wet period state (or close to it), and only $500 \mathrm{~h}$ a year were dedicated to the dry period state.

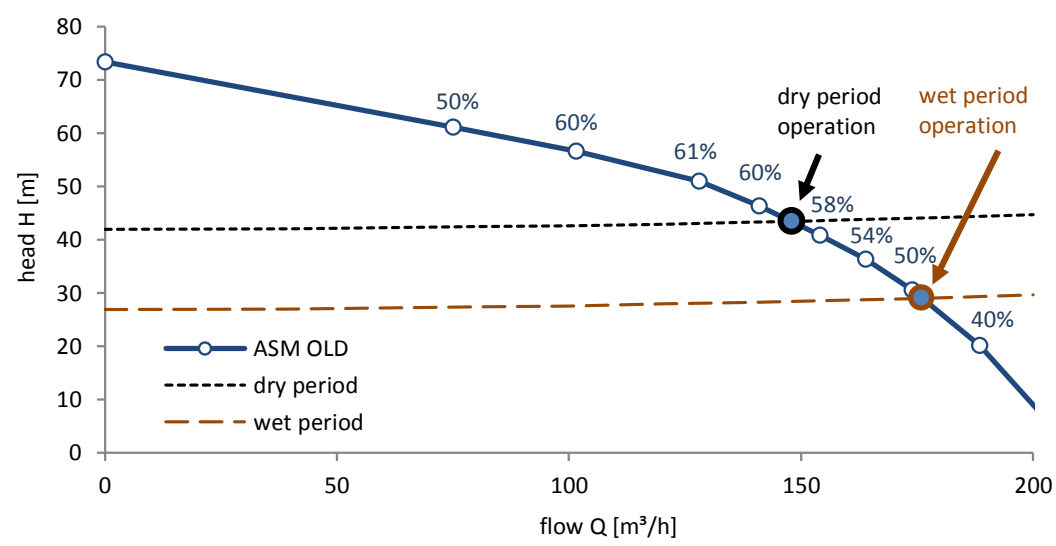

Figure 5. System curves for the dry period and the wet period, and the ASM pump curve with global efficiency information vs flow, and the working points for the dry period and the wet period.

Figure 5 displays the curves for the dry period and the wet period state of the well field in Berlin-Tiefwerder. Depending on the larger total flow rate and the higher pressure level (here, expressed as head) in the raw water pipe network, the dry period system curve was above the wet period system curve. The pump curve of the ASM pump displayed the calculated global efficiencies at different flow rates and pressure levels. Each intercept point of the pump curve and system curve was a working point of the well pump. During the dry period state, the pump operated at $43.5 \mathrm{~m}$ pressure, with a flow rate of $146 \mathrm{~m}^{3} / \mathrm{h}$, while in the wet period state, the pressure was $29 \mathrm{~m}$ at a flow rate of $176 \mathrm{~m}^{3} / \mathrm{h}$. The pump reacted to the pressure levels in raw water pipe. In between the two operational states, the volume flow increased by $20 \%$. The ASM pump had its best efficiency point at a flow rate of $125 \mathrm{~m}^{3} / \mathrm{h}$ with a global efficiency of $61 \%$. However, at the dry period working point, the pump achieved only a global efficiency of $59 \%$, and this further declined to only $49 \%$ at the wet period working point.

The variable system conditions of well fields due to the changing water demand, which are regulated by intermittent pump operation, are well known by the water suppliers [21]. However, the traditional scenario to design the groundwater well fields linked to implemented well pumps is a maximally achievable volume flow rate combined with the maximal pressure level, usual for the dry period state. The energy saving aspects or pump efficiency have not been considered intensively until now. The consequence is that the design of each implemented ASM pump considered only the dry period state, and the best efficiency is measured at this working point.

This analysis highlighted the interaction between the state of the well field operation and the state of the single installed ASM pump. In the majority (88\%) of the operation time, the investigated well pump ran out of optimal global efficiency. Especially in the wet season of the year, the ASM pump was particularly inefficient. A better adjustment of variable working points and the maximum global efficiency of each local well pump within a well field is necessary. This is an important aspect for upcoming well field optimization, and it explains the low global efficiencies derived from the well pump analyses mentioned in Section 1 [11,12]).

\subsection{Measuring the Efficiencies of ASM vs PMSM at the Adjusted Best Efficiency Point}

In the Berlin-Tiefwerder well, the conventional ASM pump was replaced by a new PMSM pump. Potential high efficiency increases were expected by using a smart combination of PMSM technology, and by adjusting the best efficiency point on common well field scenarios (see Section 3.2). Hence, the flow rates of the ASM pump ranged from $100 \mathrm{~m}^{3} / \mathrm{h}$ to $180 \mathrm{~m}^{3} / \mathrm{h}$. The new PMSM pump must operate within this range, but at $150 \mathrm{~m}^{3} / \mathrm{h}$, with the highest global efficiency based on water demand. Figure 6 presents the measured global efficiency curves over the flow of the ASM pump and the innovative 
PMSM pump. The curve of the PMSM pump apparently reaches a plateau for global efficiency at approximately $150 \mathrm{~m}^{3} / \mathrm{h}$ and higher. The best determined efficiency point of ASM pump was $61 \%$ at a flow rate of $125 \mathrm{~m}^{3} / \mathrm{h}$, and for the PMSM pump, it was $68 \%$ at a flow rate $180 \mathrm{~m}^{3} / \mathrm{h}$. Both the dry period and wet period working points were not the best efficiency points for the ASM, nor for the PMSM pump. The ASM curve showed global efficiencies of 59\% and $49 \%$ at the full demand and low demand working points, respectively. The same global efficiency of $67 \%$ was measured at the dry period and wet period working points for the PMSM pump. Accordingly, an increase of $18 \%$ in global efficiency for the wet period working point, compared to $8 \%$-points at the dry period working points, was seen for PMSM pump over the ASM pump.

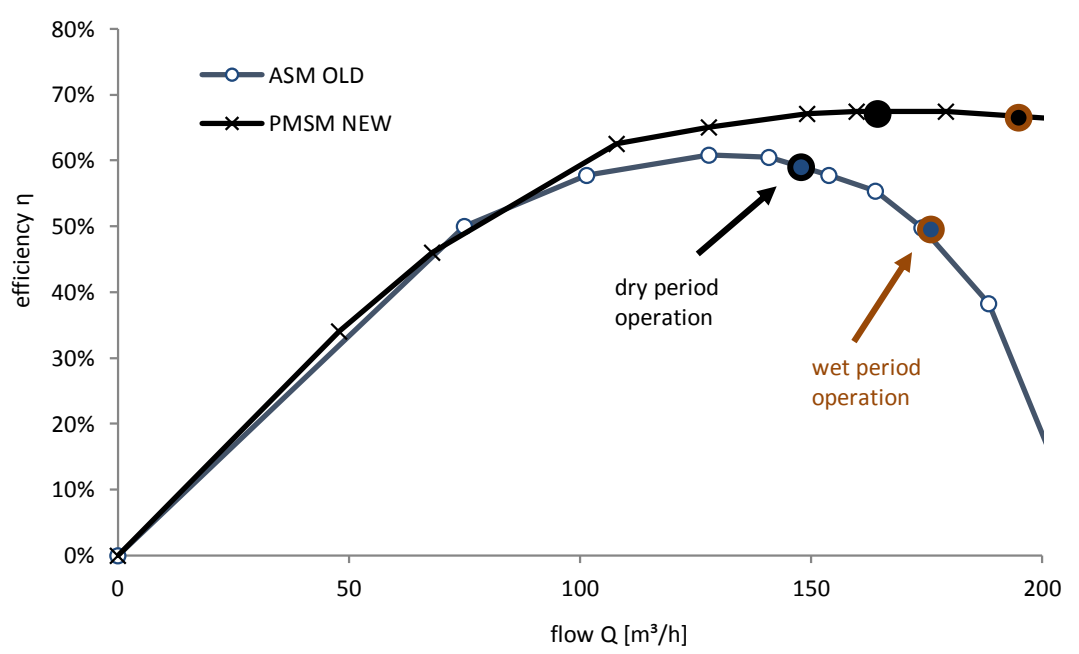

Figure 6. Global efficiency curves for the ASM and PMSM pumps vs flow and individual working points at dry period and wet period operation.

The investigations in Berlin-Tiefwerder confirm the results of Section 3.1. Apart from positive effects for energy efficiency by applying the PMSM pump, a better adaption of best efficiency points in the context of the preferred working point provides additional yields on global efficiency.

\subsection{Analysis of Energy Saving Potential with Variable Speed Operation}

The impact of well field operation on single installed well pumps was discussed in Section 3.2. In order to prevent high local flow rates in wells during winter periods, they have to be regulated. As an alternative to throttling, variable-speed operation by frequency converters offers constant flow conditions with higher global efficiencies, and significantly lower power consumption [4]. When frequency converters are connected to the local flow measurement equipment, they can respond to changes in the flow rate by controlling the pump speed [22]. Especially in dry periods, the total water demand decreases, and less pressure is necessary. In this case, the pump speed can be decreased, which is linked to a lower pressure level. This results in an overall lower energy consumption. To investigate this approach, the PMSM well pump in Berlin-Tiefwerder was equipped with an automatic flow-control, and the well was set at a constant flow rate of $150 \mathrm{~m}^{3} / \mathrm{h}$. To measure the impact of well field operation on the local well, the PMSM pump with flow-control was operated for a further period of 12 months.

Figure 7 shows the effect of the variable speed with constant flow on the measured working points. With a decreasing speed level, the pump operates at a lower head, predominantly at the wet period scenarios. The system curves for dry period and wet period scenarios, each cutting the PMSM pump curves, belonged to the speed levels of $93 \%$ and $83 \%$, respectively. Additionally, at $100 \%$ and $78 \%$ speed, two peak operation scenarios were measured because of unusually high as well as low water demands. 


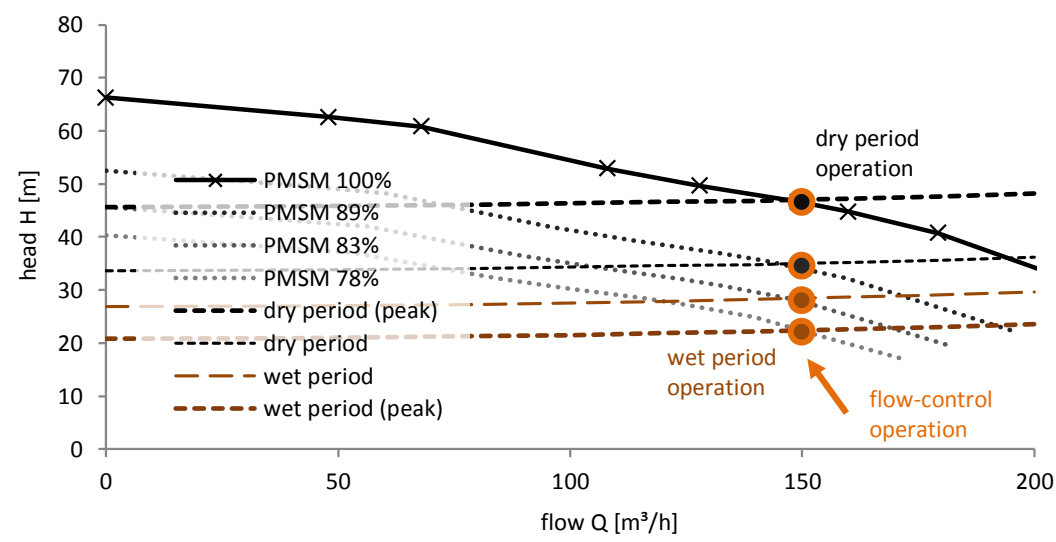

Figure 7. System curves for dry period and wet period operations, and PMSM pump curves vs flow (at $100 \%, 89 \%, 83 \%$, and $78 \%$ speed levels), and the associated working points.

Figure 8a presents the measured effective power at variable speeds, as well as the calculated specific energy consumption vs flow (Figure 8b). All of the operational points at a constant flow are highlighted. At dry period peak operation at a flow rate of $150 \mathrm{~m}^{3} / \mathrm{h}$, an effective power of about $28 \mathrm{~kW}$ was required, and the corresponding specific energy consumption was $0.187 \mathrm{kWh} / \mathrm{m}^{3}$. At the wet period, the effective power and specific energy consumption was reduced to $17.1 \mathrm{~kW}$ and $0.114 \mathrm{kWh} / \mathrm{m}^{3}$, respectively, which further reduced to $13.5 \mathrm{~kW}$ and $0.09 \mathrm{kWh} / \mathrm{m}^{3}$, with the lowest demand being at the wet period operation. By turning the working point from the dry period and the ideal wet period operation, a considerable reduction in measured effective power and calculated specific energy consumption was achieved. The difference between both operational peak states was $14.5 \mathrm{~kW}$ or $0.1 \mathrm{kWh} / \mathrm{m}^{3}$, respectively.

(a)

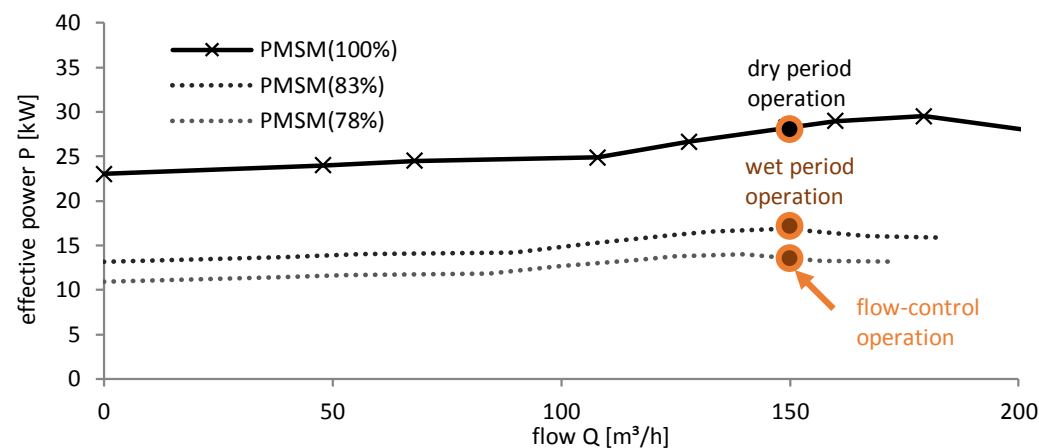

(b)

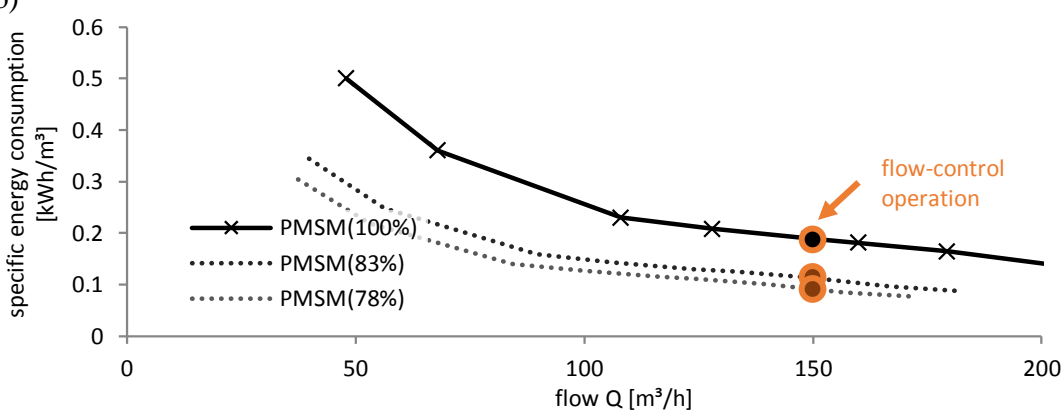

Figure 8. (a) Effective power and (b) specific energy consumption vs flow for the investigated PMSM pump at $100 \%, 83 \%$, and $78 \%$ speed levels.

Table 2 further quantifies these results with respect to the total annual energy savings at this specific well. For an exact comparison of the ASM and PMSM pump, the operating time in each scenario was considered. The ASM pump had a total energy consumption of about 114 MWh per year, 
while the total energy consumption of the PMSM pump was approximately $72 \mathrm{MWh}$ per year. The PMSM pump required 37\% less energy than the ASM pump in a year with the same working time. With respect to the specific energy consumption, the PMSM pump reached an efficiency increase of about $0.05 \mathrm{kWh} / \mathrm{m}^{3}$, resulting in cost savings of about $6800 € /$ a (based on total energy saving, with calculated electricity price $0.163 € / \mathrm{kWh}$ ), or greenhouse savings of 22 tons $\mathrm{CO}_{2}$ a year (based on the reduction of energy consumption, with a calculated German energy mix of $0.527 \mathrm{~kg} \mathrm{CO}_{2} / \mathrm{kWh}$ ).

The calculation in Table 2 needs to consider the total annual flow. The non-speed controlled ASM pump delivered $690,000 \mathrm{~m}^{3} / \mathrm{a}$, whereas the PMSM pump transported only $600,000 \mathrm{~m}^{3} / \mathrm{a}$. To compensate for the difference in flow volume, an additional PMSM pump with an operational time of $600 \mathrm{~h}$ per year is necessary. Accordingly, an additional energy demand of $11.6 \mathrm{MW} / \mathrm{a}$ will be required. By taking into account the additional energy requirements, the PMSM pump still needs $30 \mathrm{MW} / \mathrm{a}$ less energy (equivalent to $26 \%$ savings) compared to the ASM pump. This results in a $4900 €$ (calculated electricity price $0.163 € / \mathrm{kWh}$ ) annual cost reduction for the well, which is equivalent to a reduction of 15.9 tons of $\mathrm{CO}_{2}$ emissions (calculated German energy mix $0.527 \mathrm{~kg} \mathrm{CO}_{2} / \mathrm{kWh}$ ).

Table 2. Calculation of energy savings based on the measured operation data.

\begin{tabular}{|c|c|c|c|c|c|c|}
\hline Submersible Pump with ASM & t (h/a) & $Q\left(\mathrm{~m}^{3} / \mathrm{h}\right)$ & $\mathrm{H}(\mathrm{m})$ & $\eta(\%)$ & $\mathbf{P}(\mathbf{k W})$ & $\mathrm{E}\left(\mathbf{k W h} / \mathrm{m}^{3}\right)$ \\
\hline Dry period operation & 500 & 146 & 43.50 & 58.96 & 29.32 & 0.20 \\
\hline Total & 4000 & 689,000 & & & 113,685 & 0.17 \\
\hline Submersible pump with PMSM & $t(h / a)$ & $Q\left(\mathrm{~m}^{3} / \mathrm{h}\right)$ & $\mathrm{H}(\mathrm{m})$ & $\eta(\%)$ & $\mathbf{P}(\mathbf{k W})$ & $\mathrm{E}\left(\mathrm{kWh} / \mathrm{m}^{3}\right)$ \\
\hline Wet period operation & 3500 & 150 & 27.87 & 66.15 & 17.20 & 0.11 \\
\hline Dry period (peak) operation & $\mathrm{t}(\mathrm{h} / \mathrm{a})$ & $\mathrm{Q}\left(\mathrm{m}^{3} / \mathrm{a}\right)$ & & & $\mathrm{P}(\mathrm{kWh} / \mathrm{a})$ & $\Delta \mathrm{E}\left(\mathrm{kWh} / \mathrm{m}^{3}\right)$ \\
\hline Total & 4000 & 599,800 & & & 72,014 & 0.12 \\
\hline Difference & & $-89,200$ & & total saving & $-41,671$ & -0.05 \\
\hline \multirow[t]{2}{*}{ Additional * } & 595 & 89,250 & & & 11,602 & 0.13 \\
\hline & & & & total saving * & $-30,068$ & \\
\hline
\end{tabular}

\section{Conclusions}

Submersible well pumps working in groundwater wells are the main reason for high energy consumption in water collection systems. These machines still work with a low global energy efficiency $(<50 \%)$. In the present study, measures to increase the global efficiency of the submersible well pumps linked to real electrical energy savings are suggested. Thereby, the impact of the well field operation on pump efficiency, and the suitability of the innovative PMSM pump systems in groundwater wells is discussed.

All measures are associated with measurements under real well field working conditions. Focusing on two test wells at two different waterworks in Berlin and Hamburg, conventional submersible ASM well pumps were compared with innovative PMSM pumps. The PMSM technology offers highly efficient motors for well application, but this is quite new for water suppliers, and it has rare practical references, as well as a lack of long-term experience.

Situation analyses reveal that the global efficiency of each local well pump is directly associated with the entire well field operation. The water supply currently employs well management strategies with intermittent operation of the installed ASM pumps (on/off) that directly influence the local pressure level and the flow rate of each pump, and the corresponding global efficiency. Measurement campaigns confirm that decreasing the water demand may diminish the local well pump efficiency by up to $10 \%$-points, due to the unadapted design of the pumps' working point. Currently, the design point at the best efficiency is chosen for the maximum pressure level, corresponding to the maximum flow in the well field. To optimize the energy requirements, water suppliers should analyze their daily routines of pump use, as well as the annual raw water demand and the prioritized scenarios 
of well field operation. Each pump that is part of a well field should be designed to operate at the best efficiency point that is directly connected to the most frequently occurring well field operating scenario. This includes the fact that each pump must still be able to run at the maximum pressure level to meet demand peaks, but at a lower than optimal efficiency.

Measurements in Hamburg-Billbrook confirm that a global efficiency of up to $65 \%$ can be reached with an ASM pump, and an enhancement to over 70\% is possible with new PMSM technology. An energy consumption reduction of $9.6 \%$ was measured with the new PMSM motor type in a similar well field operation. Measurements in Berlin-Tiefwerder present the adjustment of the best efficiency point for a new PMSM pump by comparison with the original ASM pump. In the case of the individual variable water demand, the global efficiency increase goes up from $8 \%$-points to $18 \%$-points. It can be expected that other pumps within this well field have a similar potential regarding the efficiency increase. This shows the need for an overall efficiency optimization procedure that includes all well pumps together within a well field being adapted to variable operation conditions.

It must be considered that additional equipment, such as a frequency converter and an electrical filter, are necessary for PMSM pumps, and this leads to further requirements in the electrical infrastructure and the well buildings. The water supplier must make their decisions regarding PMSM pumps based on life-cycle cost analyses and operational risks. With respect to the overall environmental analysis, it should be mentioned that the production of permanent magnets requires rare earth elements, which may be connected with considerable environmental burdens in mining, refining, and processing. Recycling of such metals today is in the experimental stage only.

The application of frequency converters enables speed control for individual pump operation, and it offers new options for the control of the water delivery of each well in the water supply. Measurements in Berlin-Tiefwerder show that energy savings of up to $25 \%$ are possible. These high potentials are expected only for larger well fields with varying water demands (which is the regular case for larger water utilities). A lower total flow requires a reduction in the number of operating pumps, and this results in lower pressure levels for each well. Each local well pump can be adapted by decreasing its speed to intermittent operation, and this avoids negative side effects. As this strategy is usable for ASM and PMSM pumps, water suppliers can adopt this technique to their existing pumps.

Author Contributions: Conceptualization, M.B., A.S., R.B. (Ricardo Blank), and M.E.; Data curation, M.B., E.M., and R.B. (Ralf Binz); Formal analysis, M.B.; Investigation, E.M., and R.B. (Ralf Binz); Methodology, E.M., and R.B. (Ralf Binz); Project administration, M.B., A.S., and R.B. (Ricardo Blank); Resources, E.M. and R.B. (Ralf Binz); Supervision, M.E.; Validation, M.B., A.S., and R.B. (Ricardo Blank); Visualization, M.B.; Writing-original draft, M.B.; Writing一review \& editing, M.B., A.S., R.B. (Ricardo Blank), and M.E.

Acknowledgments: This work is part of the project ENERWAG, which is funded by the Federal Ministry for Economic Affairs and Energy of Germany and the German Association of Gas and Water (DVGW) within the project ENERWAG, and is gratefully acknowledged. The authors give thanks also for the professional support of the technical staff from Hamburg Wasser and Berliner Wasserbetriebe.

Conflicts of Interest: The authors declare no conflict of interest.

\section{References}

1. Branchenbild der Deutschen Wasserwirtschaft; wvgw Wirtschafts- und Verlagsgesellschaft Gas und Wasser: Bonn, Germany, 2015.

2. Statistisches Bundesamt. Umweltnutzung und Wirtschaft. Tabellen zu den umwelt-ökonomischen Gesamtrechnungen Teil 2: Energie; Statistisches Bundesamt: Wiesbaden, Germany, 2015.

3. Beck, M.; Ernst, M. Kooperationsprojekt zur Energieeffizienz in der Wassergewinnung; Energie Wasser-Praxis: Bonn, Germany, 2016; Volume 5, pp. 78-83.

4. Madsen, H.; Refsgaard, A.; Falk, A. Energy optimization of well fields. Ground Water 2009, 47, 766-771. [CrossRef] [PubMed]

5. Hansen, A.K. Optimization of Well Field Management; Technical University of Denmark (DTU): Kgs. Lyngby, Denmark, 2011.

6. Gülich, J.F. Centrifugal Pumps, 2nd ed.; Springer: Berlin/Heidelberg, Germany, 2014. 
7. Stoffel, B. Assessing the Energy Efficiency of Pumps and Pump Units-Background and Methodology; Elsevier Ltd.: Amsterdam, The Netherlands; Oxford, UK; Cambridge, MA, USA, 2015.

8. Reeves, D.T.; Bower, J.; Nevěřil, J.; Janigro, A.; Schofield, S. European Guide to energy Efficiency for Single-Stage Centrifugal Pumps; EC Joint Research Centre, European Commission: Varese, Italy; EUROPUMP: Brussels, Belgium, 2003.

9. Takacs, G. Electrical Submersible Pumps Manual Design, Operations, and Maintenance, 2nd ed.; Gulf Professional Publishing: Cambridge, MA, USA; Oxford, UK, 2018.

10. Life Cycle Costs: A Guide to LCC Analysis for Pumping Systems; Hydraulic Institute: Parsippany, NJ, USA; Europump: Brussels, Belgium; U.S. Department of Energy: Washington, DC, USA, 2001.

11. Plath, M.; Wichmann, K. DVGW-Information Wasser Nr. 77 zur Energieeffizienz; Energie Wasser-Praxis: Bonn, Germany, 2011; Volume 1, pp. 58-60.

12. Staub, M.; Vautrin, N.; Rustler, M. D 4.1 OptiWells-1 Final Synthesis Report; Kompetenzzentrum Wasser Berlin: Berlin, Germany, 2012.

13. EU Regulation No 640/2009. Implementing Directive 2005/32/EC of the European Parliament and of the Council with Regard to Ecodesign Requirements for Electric Motors; Official Journal of the European Union: Brussels, Belgium, 2009; L 191/26-34.

14. EU Regulation No 547/2012. Implementing Directive 2009/125/EC of the European Parliament and of the Council with Regard to Ecodesign Requirements for Water Pumps; Official Journal of the European Union: Brussels, Belgium, 2012; L 165/28-36.

15. EU Regulation No 640/2009. BS 60034-30-1: Rotating Electrical Machines_Part 30-1: Classes of Line Operated AC Motors; BSI: London, UK, 2014.

16. BS 16480: Pumps. Minimum Required Efficiency for Rotodynamic Water Pumps; BSI: London, UK, 2016.

17. Press release: Best Energy Source Keeps Energy Saving. Congress for efficient electrical drives. Braunschweig, Germany. 2016. Available online: http:/ / copperalliance.de/docs/librariesprovider3/press-releases/de/ pi_ptb-kongress2016.pdf?sfvrsn=0 (accessed on 13 September 2018).

18. H\&\#xFC; bner, M. Durch welche Komponente kann man Die Effizienz in der Wasserversorgung steigern? docplayer.org/18046799. Presented at the 1st Thüringer Trinkwassertagung, Germany, Jena, 6-7 April 2016.

19. Butlin, D.M. The effect of motor slip on submersible pump performance. Paper presented at the ESP workshop, Houston, TX, USA, 29 April-1 May 1991.

20. Schmidt, T. Energieeffiziente Pumpensysteme für die Wasserversorgung; $\Delta$ p: Aichtal, Germany, 2017; Volume 1, pp. 28-30.

21. Nolen, K.B.; Gibbs, S.G. How to match submersible pumps to well performance. World Oil 1985, 200, 41-45.

22. Kelley, R.S. Productivity determination and pump resizing using variable-speed electric submersible pumps. J. Pet. Technol. 1980, 32, 1503-1508.

23. Pérez-Sánchez, M.; Sánchez-Romero, F.J.; Ramos, H.M.; López-Jiménez, P.A. Energy Recovery in Existing Water Networks: Towards Greater Sustainability. Water 2017, 9, 97. [CrossRef] 